\title{
THE IMPLEMENTATION OF A PHOTOGRAMMETRIC PROCEDURE FOR THE ADJUSTMENT OF THE OLD RASTER CADASTRAL PLANS
}

\author{
Si youcef, Kamel ${ }^{1 *}$; Boukerch, Issam ${ }^{1}$; Belhouari, Fatima Z. ${ }^{1}$; Seddiki, Akram M. ${ }^{1}$; Takarli, Bachir ${ }^{1}$ \\ ${ }^{1}$ Agence Spatiale Algérienne, Centre des Techniques Spatiales, Arzew, Alegria - ksiyoucef@cts.asal.dz \\ Commission IV
}

KEY WORDS: Multifunctional cadaster, Cadastral data, old Orthophotos, simultaneous adjustment

\begin{abstract}
:
Algeria faces challenges of globalization. It classifies the establishment of the national general urban and rural territory cadastre as top priority. The National Cadastre Agency has implemented a policy aimed at improving the quality and accuracy of the resulting documentation, in order to widen the scope of the latter in the various fields.

Since the launching of the first operations to establish the general cadastre of the national territory, the graphic cadastral documentation which was carried out based on aerial images (ortho-photographs or restitution plans) present mismatch either between the external borders or between the section plans that compose the communal (municipal) cadastral plane.

This article describes one of the simultaneous plane adjustment techniques inspired by the aero triangulation used in photogrammetry. In a first step, we built the photogrammetric unit where we consider the cadastral planes as photogrammetric models. In a second step, the constructed units will be used to form a superstructure covering a very large area like in the photogrammetric block case. Finally, this superstructure is adjusted, where the discrepancies are reduces relatively between these section plans using Tie Points (TP) and absolutely by relying on an optimal number of Ground Control Points (GCP) in the terrain system suitably distributed on the block. This technique makes it possible to preserve the relationships between the data in a precise way and to guarantee the continuity in the acquisition of the data which can be added later. It also makes it possible to solve the problem of the overlap between the isolated section plans due to the non-optimal distribution, the insufficiency, or the absence of control points.

The evaluation results obtained after the experiments report that the proposed adjustment technique is efficient to solve such a problem.
\end{abstract}

\section{INTRODUCTION}

The cadastral plan represents the municipal territory with the collection of the legal information necessary for the identification of the owners, which ensures good management, and an exact representation of the national territory at large scales.

A detailed representation in the form of orthophotography or restitution plans facilitates land reforms, real estate transactions, and ensures security of tenure. Nevertheless, the unification of these plans into a GIS database present some challenges in the case of the Algerian cadastre.

The graphical cadastral documentation in Algeria is organised in units covering a municipality (called commune) that represent the smallest administrative unit. Each municipality territory is then split into cadastral sections. A cadastral section, by definition, is a part of the municipality territory delimited by relatively permanent landscape elements and that can be represented on the scale of $1 / 5000$ in a standardized sheet format $(51.4 \mathrm{~cm} * 76 \mathrm{~cm})$. These sections are made based on orthophotos of the same scale covering the whole municipality.

After introducing the GIS tools to the cadastre, the National Cadastre Agency launched a program to digitize and integrate these cadastral plans into a unified database. Here, many problems arise, among them we can cite:

- The non-presence of the reference system, hence the represented coordinates are useless for some sections,

- Some plans does not have coordinates and ticks, so these sheets were independent but the section sheet is internally correct,

- Some sheets had erroneous ticks and coordinates,

This lead to difficulties in the establishment of the unified cadastral database. A first try to deal with this problem is the georeferencing using GPS, where four details from the section plan are selected and observed on the field by GPS and used to calculate an affine transformation. This method, even if it enhances the quality of the georeferencing, but it is slow, expensive and time consuming, therefore it is almost impossible to generalise it to national territory. Even using this methodology, the selection of four points is not far from the strict minimum and does not guarantee the final quality, because the points can be misinterpreted on the plan or on the ground. This lead to some discrepancies and overlaps on the borders of sections.

Usually, the sections are displaced, disoriented, and sometimes have scale errors. Several questions may arise such as: Is it only related to digitization? Are these errors due to the boundaries misidentification? Or are the basic documents badly made?

Discrepancies or overlaps take two forms of geometric representations, their presence in the thematic information layers of the cadastre does not only influence the metric quality of the blocks and plots, but also influence the results of the requests, which decreases the quality of cadastral information particularly in the context of the multifunctional cadastre where the exchange of data between the cadastre and the different public bodies is very important. The two forms of overlapping are:

Form 1: the holes, which are translated by an uncovered surface due to a bad orientation of the section, an offset in the $x, y$ direction or a scale factor enlarging or reducing the section compared to the bordering section (Figure 1). 


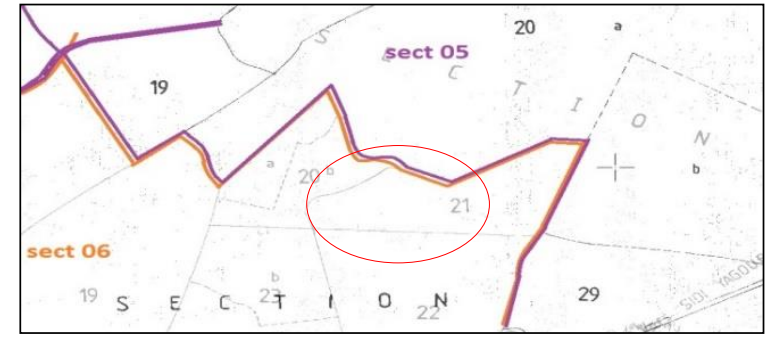

Figure 1. The first form of overlapping problem.

Form 2: Like the first form, overlapping between sections may exist, but their influence on the quality of cadastral information is heavier compared to the first form because these overlaps will systematically introduce overlaps between the adjacent real properties.

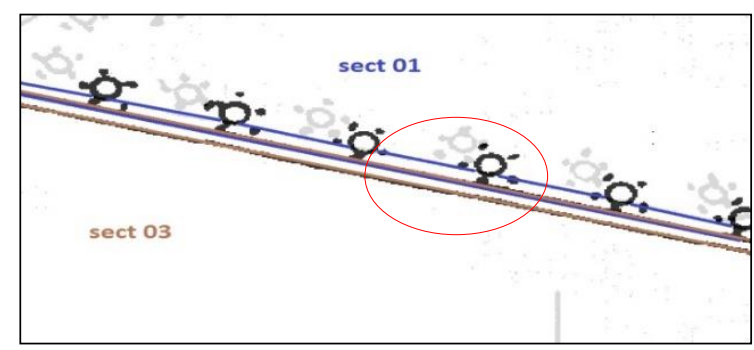

Figure 2. The second form of overlapping problem.

To resolve the problem of discrepancies, it is necessary to identify its origin, in other words, identify the type of document and in which stage it is used. We propose three main steps to solve the problem:

Section partitioning procedure: the limits of the new cadastral section must be carried using the limits of the bordering sections that are already cadastred.

Quality of the basic support document: errors made during orthorectification can create inaccuracies in the positions of the limits.

Digitization of graphic documentation: if the agent in charge of this digitization mission does not respect the drawing rules in topological mode.

\section{METHODOLOGY}

To minimize the overlap between the cadastral sections, we propose an adequate solution to this problem by the implementation of algorithms of a planimetric adjustment of the Independent models, which can adjust the planes of sections simultaneously.

The method we propose is inspired from photogrammetric adjustment techniques (adjustment by independent models). The model is then for us is the cadastral section plane.

Simultaneous adjustment of different plans in the same reference system proves to be an essential technique allowing on the one hand to preserve the relationships between the data in a precise way and on the other hand to guarantee a continuity in information acquisition which can be added later in the update revision.

In the block adjustment we use the section plans which are considered by analogy to photogrammetric models, the section plans will be used to form the superstructure which is called block, This superstructure is adjusted simultaneously between the units composing the block and to the field reference system by relying on an optimal number of GCPs suitably distributed over the block.

This approach has been proposed by (Klebanov, Doytsher, 2009). The similarity transformation is used and has been evaluated on simulated data. In this paper, the transformation used is the affine transformation that allow correcting the skewness (the nonperpendicularity of the axis) and the scale difference in both axis, which can be introduced in the cadastral section plan scanning process.

\subsection{Method overview}

We summarise the proposed algorithm in the next detailed diagram showing the different steps to obtain the six adjustment parameters for each section (Figure 3).

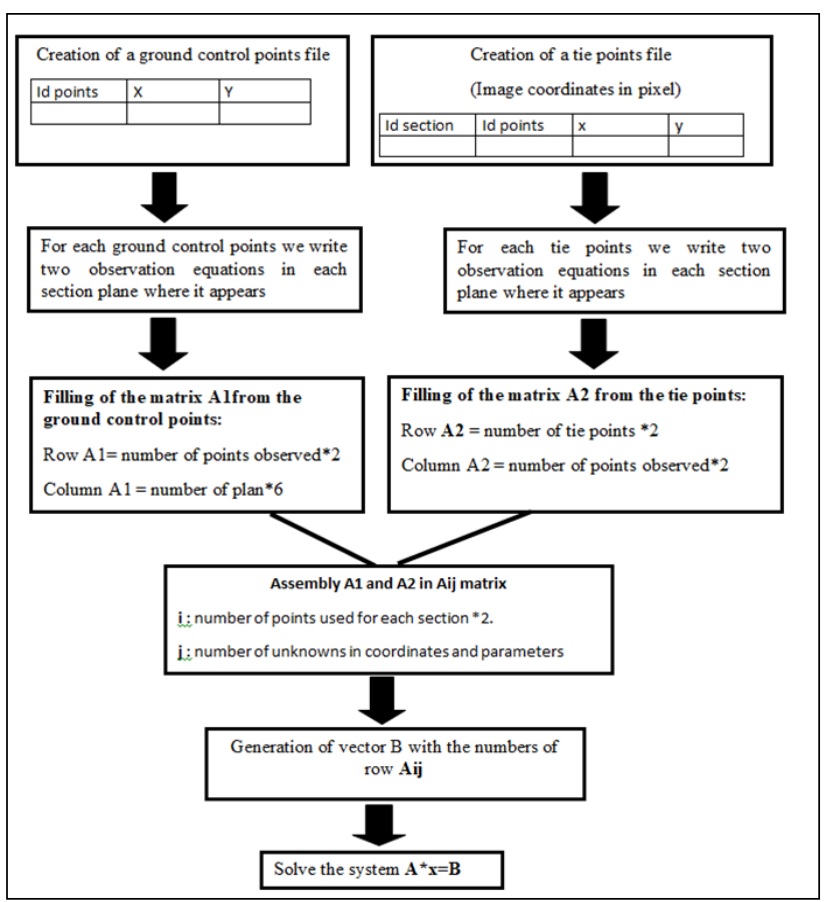

Figure 3. Framework of the proposed method.

\subsection{Adjustment by independent section}

The adjustment by independent section is the most commonly used technique, it is proposed by almost all the geosoftwares, where the user have to make a georeferencing of the section plans independently of each other using a sufficient number of known points, these points can be either ground collected points or the ticks on the plan. Generally, the affine transformation (equation 1 ) is used to model the transformation between the image and the ground coordinates systems.

This technique is simple to implement, but it has some limitations:

It cannot guarantee a correct and continuous assembly of the various section plans and their connections. The connection between the different systems is never guaranteed because each section plane has its own characteristics. (Deformation, archiving, local system, precision, scale, support, etc.).

This technique can be used as a method of derivation of an approximate solution for a global adjustment in the case of the use of a nonlinear transformation, or to give an outline on the deformations in order to determine the transformation to be used. 
To solve the problem of overlapping generally we use the affine transformation with six parameters by section (a, b, c, d, Cx, Cy) to correct one rotation, two differential scale factor and translations in the two directions, and a skewness error.

\subsection{Simultaneous adjustment of sections}

Block compensation is achieved by simultaneous absolute orientation of all the section planes. This georeferencing procedure is based on one hand, on a relative adjustment between the different local systems which minimizes the relative differences between the coordinates of the junction points (tie point), and on the other hand, an absolute adjustment of all the systems at the same time compared to the reference system which minimizes the absolute deviations on the coordinates of the control points.

The adjustment technique makes it possible to preserve the relationships between the data in a precise way and to guarantee continuity in the acquisition of the data which can be added later, it also makes it possible to solve the problem of the isolated calibration of the plans which is based on a unique transformation binding each local system independently to the system without taking into account the characteristics of other systems.

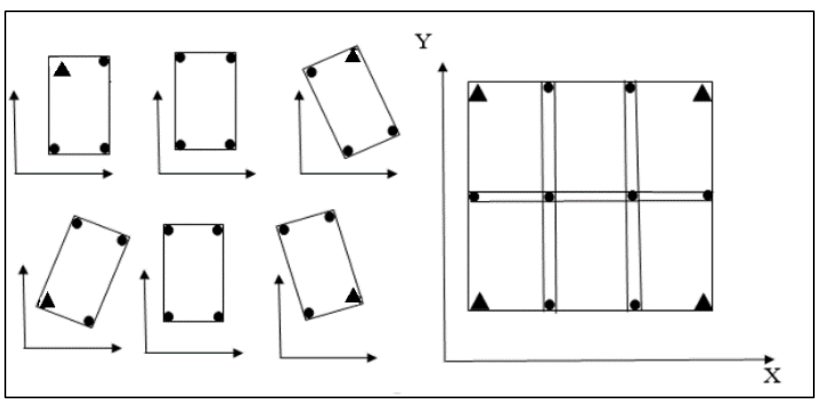

Figure 4. Simultaneous adjustment of sections bloc.

\subsection{Observation equation of affine transformation}

$\left.\left[\begin{array}{l}\mathrm{X} \\ \mathrm{Y}\end{array}\right]_{\mathrm{i}}=\left[\begin{array}{ll}\mathrm{a} & \mathrm{b} \\ \mathrm{c} & \mathrm{d}\end{array}\right]\left[\begin{array}{l}\mathrm{X} \\ \mathrm{y}\end{array}\right]_{\mathrm{ij}}+\left[\begin{array}{c}\mathrm{Cx} \\ \mathrm{Cy}\end{array}\right]_{\mathrm{j}}=\left[\begin{array}{cc}1 & \gamma \\ 0 & 1\end{array}\right]_{\mathrm{i}}\left[\begin{array}{cc}\lambda \mathrm{x} & 0 \\ 0 & \lambda \mathrm{y}\end{array}\right]_{\mathrm{j}}\left[\begin{array}{cc}\cos \alpha & -\sin \alpha \\ \sin \alpha & \cos \alpha\end{array}\right]_{\mathrm{Y}}^{\mathrm{X}}\right]_{\mathrm{ij}}+\left[\begin{array}{c}\mathrm{Cx} \\ \mathrm{Cy}\end{array}\right]_{\mathrm{j}}$

Where $\quad c x=$ translation in $\mathrm{x}$

$c y=$ translation in $\mathrm{y}$

$\lambda x=\mathrm{X}$ scale

$\lambda y=\mathrm{Y}$ scale

$\gamma=$ system orthogonality defect (skewness).

$\alpha=$ rotation angle

The equation 1 can be rearranged as:

$\left[\begin{array}{l}X i \\ Y i\end{array}\right]=\left[\begin{array}{llllll}x & y & 0 & 0 & 1 & 0 \\ 0 & 0 & x & y & 0 & 1\end{array}\right]_{i j}\left[\begin{array}{c}a \\ b \\ c \\ d \\ c x \\ c y\end{array}\right]_{j}$

Where $i=$ point number

$j=$ the section number

$x, y=$ coordinates of the point $\mathrm{i}$ in the section $\mathrm{j}$

$X, Y=$ coordinates of the point on the ground

\section{RESULTS AND EVALUATION}

For the evaluation of the adjustment method we used two different datasets, the first one are cadastral sections scanned at 300 DPI (tiff format) and at the scale 1/5000 of a rural area acquired from the local cadaster direction. The second dataset is composed of 12 orthoimages of another area.

These datasets are used to validate the methodology on two different situations.

The first is the georeferencing of a set of section plans, these plans have coordinates and ticks that can be used as control points for the simultaneous block georeferencing.

In the second situation, the dataset is composed of scanned raw orthophotos that have not any information allowing the georeferencing. The orthophotos as acquired from the cadaster agency where roughly referenced with very bad quality. So, the dataset is used in a way to demonstrate the possibility of assembling the whole set of orthophotos relatively to the first one, by supposing its image coordinates as control points coordinates and all the other images are transformed by the mean of tie points only. This way, and using the proposed algorithm, all the images are transformed to be in the first image coordinate system with a minimum of discrepancies between them. The resulting images that are in a unified coordinate system can be used in a mosaicking process to get a whole orthophotos covering the municipality that can be georeferenced by an optimal number of control points when GPS receivers is available from the central cadaster agency.

\subsection{Georeferencing of independent section plans}

At first, we georeferenced the scanned section plans independently using ArcGIS using ground control points. Practically it is difficult to find the lists of the points used for the creation of these documents. The georeferencing is currently done using the ticks of the map grid. It is noteworthy that there are some section planes without grids, so they are georeferenced either by geometric correction w.r.t the adjacent referenced sections or with GPS points recognized on the section plane.

The residual indicates the accuracy of the georeferencing and therefore its quality, an example of the georeferencing result is presented in the next figure.

\begin{tabular}{|c|c|c|c|c|c|c|c|}
\hline \multicolumn{3}{|c|}{ 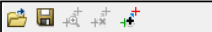 } & \multicolumn{2}{|c|}{ Erreur QM : } & \multicolumn{2}{|l|}{ Forward:0,491889 } & \multirow[b]{2}{*}{ Residual_y } \\
\hline & Lier & Source $X$ & Source $Y$ & $x$ Carte & Y Carte & Residual__x & \\
\hline 目 & 1 & 6,580692 & 7,953037 & 368000,000000 & 4009000,000000 & $-0,563753$ & $-0,092608$ \\
\hline 可 & 2 & 22,253565 & 6,826087 & 370000,000000 & 4009000,000000 & 0,571465 & 0,172611 \\
\hline 可 & 3 & 27,033337 & 18,373767 & 370500,000000 & 4010500,000000 & $-0,466188$ & $-0,234129$ \\
\hline 讨 & 4 & 7,423782 & 19,779980 & 368000,000000 & 4010500,000000 & 0,434883 & $-0,0862018$ \\
\hline 目 & 5 & 15,551425 & 23,156569 & 369000,000000 & 4011000,000000 & 0,0235929 & 0,240327 \\
\hline & & & & I'I & & & , \\
\hline & nent 2 & & Transformation & Transfo & mation de ler ordre & & \\
\hline & Minu & ondes & Forward R & sidual Unit : Unkn & & & \\
\hline
\end{tabular}

Figure 5. Example of Georeferencing accuracy results.

At the aim of designing a communal scale database (DB), we proceed by assembling the sections in a unique reference. We observed the presence of overlap between adjacent sections as shown in Figure 6. We notice a bad continuity between the limits of the section in red and the adjacent section in black Figure 6 (a and $b$ ). 


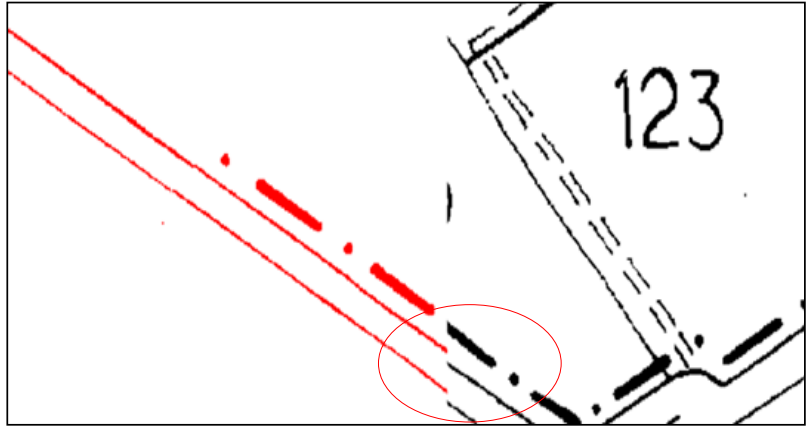

(a)

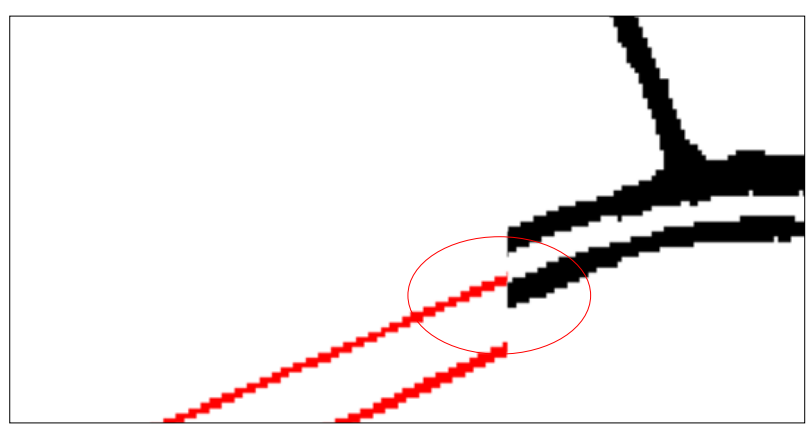

(b)

Figure 6. Results after georeferencing in an independent approach

After the detection of these different anomalies on all sections, we propose an approach for adjusting the block of sections as a whole.

\subsection{Simultaneous sections block adjustment}

In this experimentation, a block of six adjacent sections planes are compensated in planimetry.

This test is based on using 15 ground control points and tie points on the block. Figure 7 shows the distribution.

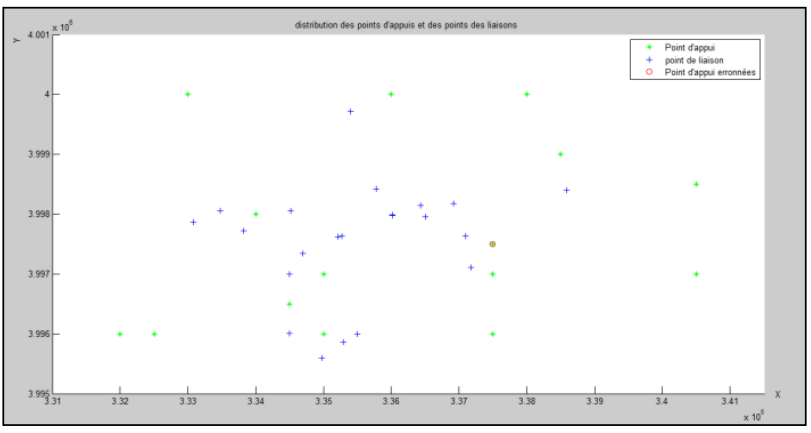

Figure 7. Distribution of ground control points (green), tie points (blue) in the first test and the erroneous GCP (red circle).

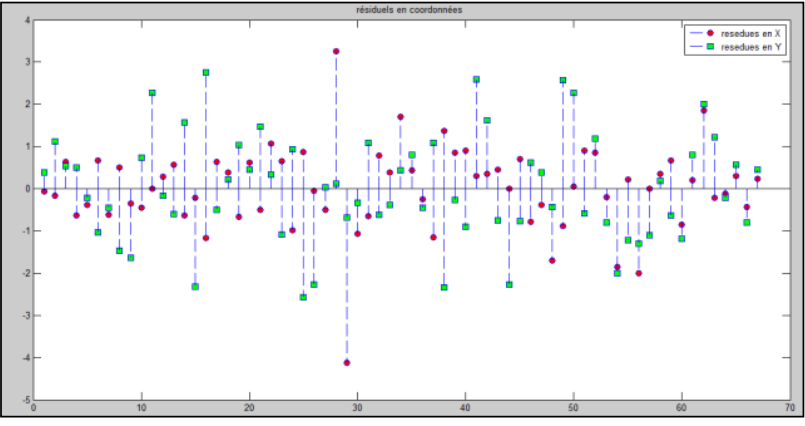

Figure 8 . The residuals of points in the first test.

From Figure 8, we notice that there is a ground control points greater than 3 times the standard deviation (erroneous point) and the residual error $\mathrm{x}$ is equal to 4 pixels, after a deep inspection this problem is due to an error on the grid tick along the y-axis. The standard deviation of the discrepancies is $\mathbf{0 . 7 8 5}$ pixel and $\mathbf{0 . 9 7 1}$ pixels in $\mathrm{X}$ and $\mathrm{Y}$ respectively.

\subsection{Execution of the adjustment program on the section plans}

According to the results obtained from various tests, we executed the adjustment program to calculate the 6 affine transformation parameters for every section And the results obtained are shown in Table 1.

\begin{tabular}{|c|c|c|c|c|c|c|}
\hline $\begin{array}{c}\text { Section/ } \\
\text { parameters }\end{array}$ & 1 & 2 & 3 & 4 & 5 & 6 \\
\hline $\mathrm{a}$ & 0.4234 & 0,4235 & 0,4243 & 0,4238 & 0,4237 & 0,4243 \\
\hline $\mathrm{b}$ & 0.0009 & 0,0006 & 0,0013 & 0,004 & $-0,0004$ & 0,0013 \\
\hline $\mathrm{c}$ & $-0,0025$ & $-0,0026$ & $-0,0034$ & 0,0027 & $-0,0025$ & $-0,0034$ \\
\hline $\mathrm{d}$ & $-0,4226$ & $-0,4227$ & $-0,4216$ & $-0,4218$ & $-0,4225$ & $-0,4216$ \\
\hline $\mathrm{e}$ & $\mathbf{3 3 1 3 6 2 , 7}$ & 332427,5 & 334749,2 & 333582,9 & 334174,9 & 334749,2 \\
\hline $\mathrm{f}$ & 3998450,6 & 4000379,6 & 4000374,5 & 3998424,0 & 3997591,6 & 4000374,5 \\
\hline
\end{tabular}

Table 1. Transformation parameters.

After the calculation of the transformation, these parameters are written in world file format (Beaudoin, 2020) and associated to their original raster files than imported under ArcGIS software, this approach is used to avoid the transformation and creation of a new raster files which is a time consuming step. The results after importing the data showed a perfect adjustment of the sections as shown in the next figure:

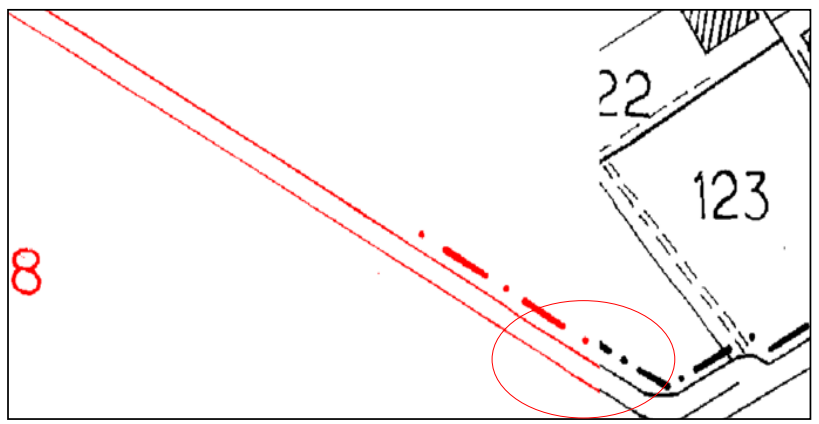

(a) 


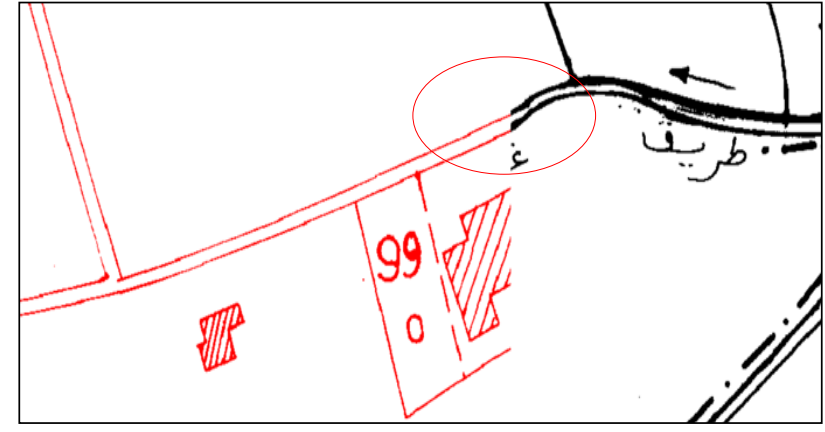

(b)

Figure 9. Adjustment results on section plans.

\subsection{Evaluation of the orthophotos adjustment program}

The second test was carried out on the block made up of 12 orthoimages on a scale of $1 / 5000$, georeferenced from the provider.

After assembling the orthophotos, we found that there are remarkable discrepancies between them as for the same evaluation (figure 10), after some investigations, it appears that the georeferencing was done using section plans that were georeferenced using the ticks. So we decided to use the proposed algorithm of block adjustment.

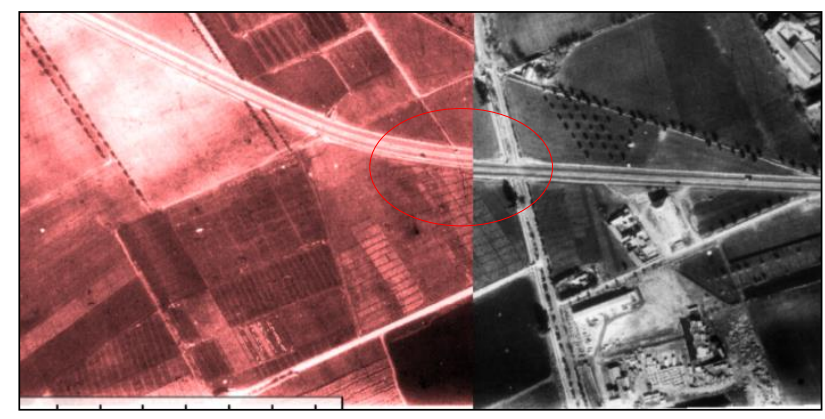

(a)

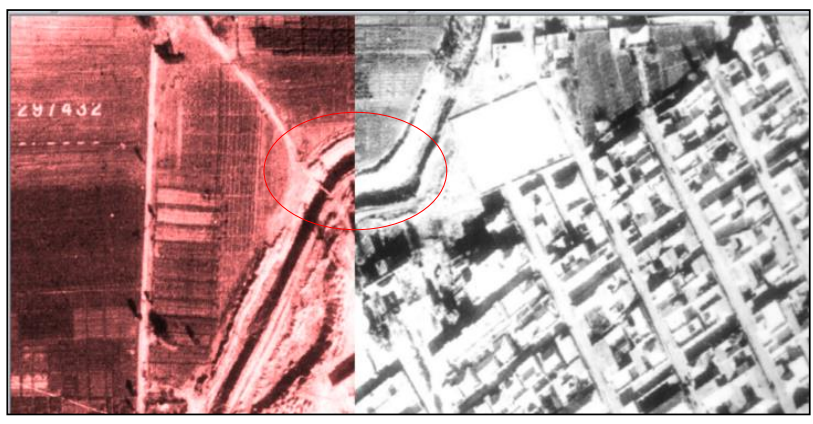

(b)

Figure 10. Results after assembling the orthophotos.

The particularity of this test was the assembling of the orthoimages without a referencing to the ground, here we use the image coordinate system of the first orthoimage as a reference system, this leads to considering the image point coordinates of this orthoimage as control points coordinates, the remaining orthoimages are tied to each other and to the reference orthoimage using tie points only. The next figure show the distribution of the reference and tie points.

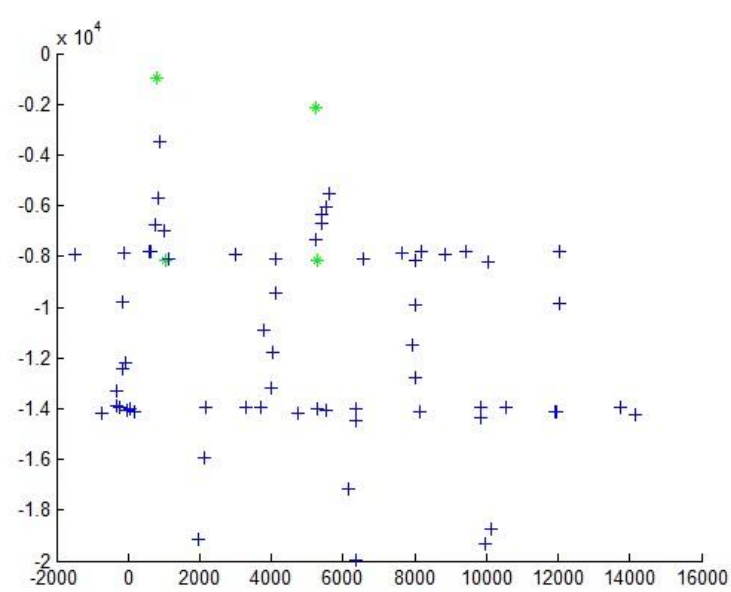

Figure 11. Distribution of reference control points and tie points

According to the test that we carried out on all orthoimages, we found that the solution is reasonable and provide an overall accuracy on tie points image coordinates equals to $\mathbf{1 . 2 8 5}$ pixel and $\mathbf{0 . 9 6 9}$ pixel in $\mathrm{x}$ and $\mathrm{y}$ directions respectively.

\subsection{Outcome of the orthoimage adjustment program}

\begin{tabular}{|c|c|c|c|c|c|c|}
\hline $\begin{array}{c}\text { ortho/ } \\
\text { parameters }\end{array}$ & 1 & 2 & 3 & 4 & 5 & 6 \\
\hline $\mathrm{a}$ & 1,01 & 1,00 & 0,99 & 1,00 & 0,99 & 0,99 \\
\hline $\mathrm{b}$ & $-0,01$ & $-0,01$ & $-0,06$ & 0,01 & $-0,00$ & 0,01 \\
\hline $\mathrm{c}$ & $-0,02$ & $-0,02$ & $-0,01$ & $-0,01$ & $-0,02$ & $-0,01$ \\
\hline $\mathrm{d}$ & $-0,96$ & $-0,96$ & $-0,96$ & $-0,96$ & $-0,97$ & $-0,97$ \\
\hline $\mathrm{e}$ & $\mathbf{9 1 4 5 , 9 5}$ & $\mathbf{5 4 1 6 , 7 9}$ & $\mathbf{1 2 2 2 , 9 9}$ & $-2827,98$ & $-4822,52$ & $-950,48$ \\
\hline $\mathrm{f}$ & $-13205,57$ & $-13153,16$ & $-13209,01$ & $-13197,53$ & $-7022,35$ & $-7132,37$ \\
\hline
\end{tabular}

Table 2. Transformation parameters.

We can notice that the parameters "a" and "d" are close to 1 because that the orthophotos are scanned at the same resolution, therefore the transformation to the first image coordinate system will not imply an important scale change.

After obtaining these transformation parameters, a restructuration in TFW format was made using these parameters, the obtained images are imported in Erdas for mosaicking, when the software asked for the coordinates system, any projection can be given and when the images are loaded the process showed a perfect assembling of the orthoimages which will lead to a good mosaic that can be georeferenced later as a unique independent image.

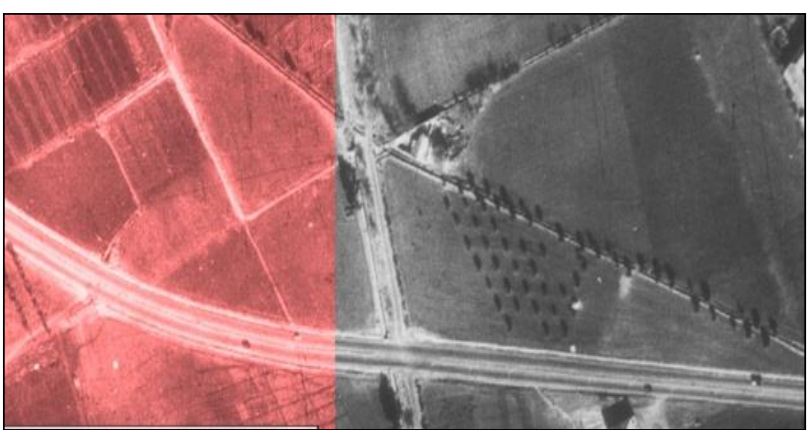




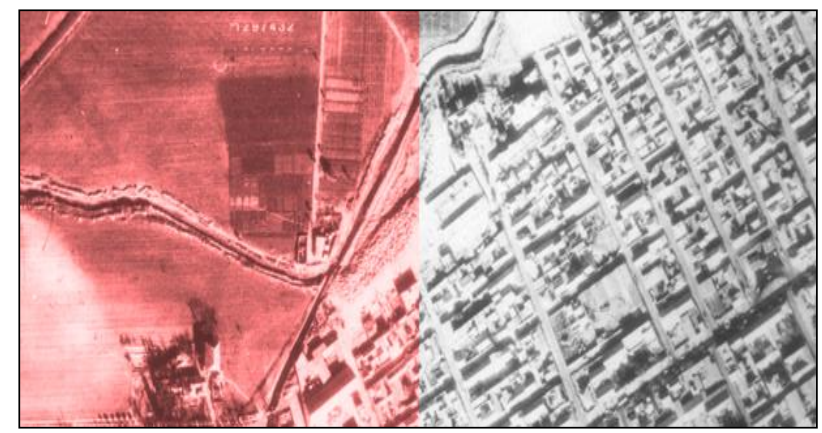

Figure 12. Continuity of details on orthoimages after adjustment.

\section{CONCLUSION}

We proposed an algorithm for section plans georeferencing by readjusting them as a whole, and we applied it to our study area. The simultaneous adjustment of the sections for our case is very good procedure for geo-references one set of section plans at a time and the results obtained depend on the quality of the cadastral plans. This technic inspired from photogrammetric block adjustment let us consider all the bloc in the same system and use the data in GIS environment. We overcome on the gaps and the overlapping areas provided by the classic independent georeferencing and guaranteed a continuity between all the section. This technic must be studied more for a large bloc if we want to consider a bigger territory.

\section{REFERENCES}

Abismail, M., Beyoud, O., 2006 : La numérisation et géoréférencement des plans cadastraux non rattachés. Master Dissertation, Centre des Techniques Spatiales, Algeria

Amer, F., 1972 : Aerial triangulation. ITC Lecture notes. Parte 1. Ayachi, M., Elyamani, M., 2012 : orthophoto numèrique au service du cadastre national. Master Dissertation, Centre des Techniques Spatiales, Algeria

Beaudoin, 2020:

http://www.omg.unb.ca/ jonnyb/processing/geotiff_tifw_forma t.html, Ocean Mapping Group, University of New Brunswick, visited 12/04/2020.

Bonneval, H., 1986 :. Photogrammetrie générale. Tome 1,. Editions Eyrolles

Ettarid, M., 2001 : Photogrammétrie Digitale. Lecture Note of Photogrammetry, UN-CRASTE-LF, Morocco.

Hamici, A., Bendaouad, A., 2005 : Etude critique et comparative entre deux solutions en vue de la numérisation des plans cadastraux ruraux (Plan cadastral, Orthophotoplan numérique). Master Dissertation, Centre des Techniques Spatiales, Algeria

Hamza, W., Boudarbala, H., 2015 : Mise en place d'une procédure d'ajustement des plans de sections pour la constitution d'une base à l'échelle communale. Master Dissertation, Centre des Techniques Spatiales, Algeria

Michael K., Yerach D.(2009) "Cadastral Triangulation: A Block Adjustment Approach for Joining Numerous Cadastral Blocks". Nordic Journal of Surveying and Real Estate Research, Secial Series Vol. 6: 53-68.
Pierre, Ravussin .,2005: étude globale de la précision du cadastre informatise. ISBN 2-88481-003-2

Rabah, A., Benmakhlouf, A., 2016 : traitement des raccords entre sections. Master Dissertation, Centre des Techniques Spatiales, Algeria 